\title{
Biseps Tendon Patolojilerinde Ultrasonografi ve Manyetik Rezonans Görüntüleme Bulgularının Karşılaştırılması
}

\author{
Comparison of Screening Findings of Ultrasonography and Magnetic Resonance \\ Imaging in Biceps Tendon Disorders
}

\author{
Gözde Sevgi YİĞİTEL ${ }^{1}$, Erdal KOMUT², Deniz Sözmen CILIZ ${ }^{3}$, \\ Turgut KÜLTÜR ${ }^{4}$, Bülent SAKMAN ${ }^{3}$
}

\author{
${ }^{1}$ Özel Keçiören Bilgi Tıp Merkezi Radyoloji Bölümü, ANKARA \\ ${ }^{2}$ Kazan Hamdi Eriş Devlet Hastanesi Radyoloji Bölümü, ANKARA \\ ${ }^{3}$ Ankara Numune Eğitim ve Araştırma Hastanesi Radyoloji Bölümü, ANKARA \\ ${ }^{4}$ Kazan Hamdi Eriş Devlet Hastanesi Fizik Tedavi ve Rehabilitasyon Bölümü, ANKARA
}

\begin{abstract}
ÖZET
Çalışmamızda omuz eklemine bağlı hastaneye başvuru şikâyetlerinin sik nedenlerinden biri olan biseps tendon patolojilerinin değerlendirilmesinde ultrasonografi (USG) ve Manyetik Rezonans (MR) görüntüleme yöntemlerini karşılaştırdık. Çalışmamızda tanı değeri tartışılmayan ve pek çok patolojide tanıda altın standart kabul edilen MR bulgularına USG incelemeyle hangi oranda yaklaşabileceğimizi araştırdık. Böylelikle hastaların inceleme konforu, maliyet etkinlik, inceleme süresi açısından öncelikle USG ile değerlendirilmesi gerekliliğini vurguladık.
\end{abstract}

Çalışmamıza Ankara Numune Eğitim ve Araştırma Hastanesi Radyoloji bölümüne omuz MR incelemesi yapılan omuz ağrısıyla başvurmuş 105 hasta dâhil edilmiştir. Hastaların USG incelemeleri Kazan Devlet Hastanesi ve Ankara Numune Hastanesi'nde MR görüntülemeden bağımsız değerlendirilmiştir. USG inceleme GE logiq9 ve Toshiba applio cihazlarında 7-12 $\mathrm{MHz}$ lineer transduserlerle yapıldı. MR görüntüleme GE 1,5 Tesla Signa Excite MR cihazıyla gerçekleştirildi.

MR'da biseps tendinozisi saptanan 3 olguda, USG'de tendinozis saptanamamıştır. USG'de tendinozis saptanan 8 olgu MR'da tendinozis açısından negatif bulunmuştur (Tablo 2). Kappa uyum katsayıs1 0,614 olup, istatistiksel olarak uyumsuz bulunmuştur. USG'nin özgüllük değeri \%92,duyarlılık değeri \%0'dır (Tablo 3). MR'da biseps tendonu parsiyel rüptürü olan 5 hastanın 2 'si USG'de saptanmıştır (Tablo 4). USG'de biseps tendonu parsiyel rüptürü için duyarlılık \%40, özgüllük \%100 bulunuştur (Tablo 5). Bu bulgular kappa uyum katsayısına göre orta derecede uyumludur. MR'da 40 hastada biseps sinoviti veya effüzyonu görülürken, USG'de 14 hastada saptanmıştır. USG'de tenosinovit veya effüzyon saptanan 4 hastada MR'da tenosinovit veya effüzyon saptanmamıştır (Tablo 6). USG'nin biseps tendon tenosinoviti veya effüzyonu için duyarlılık değeri $\% 35$, özgüllük değeri \%93'tür (Tablo 7).

USG ucuz, non-invaziv, uygulayıcının tecrübesine bağlı olarak biseps tendon patolojilerinde tanı koydurucu bir yöntemdir. Omuz ağrısıyla başvuran hastalarda MR'dan önce veya MR'la birlikte kullanılmalıdır. Böylece biseps tendon patolojilerinde maliyet etkinliği sağlanacak ve tanı konulması hızlanacaktır.
We compared ultrasonography (USG) and magnetic resonans (MR) screening methods for evaluation of biceps tendon pathologies (disorders) which are the most common causes of admission to hospital with shoulder joint complaints. In this study we evaluated in what proportion we can get results from USG similar to results from MR which is the undisputable golden standard. So we stressed the necessity of patients evaluation primarily by USG which is efficient in terms of patient comfort, cost effectiveness, and screening time.

105 patients referred to Ankara Numune Training and Research Hospital Radiology clinic with complaints of shoulder pain were included in the study USG evaluations of patients were conducted in Kazan State Hospital and Ankara Numune Training and Research Hospital independently from MR evaluation. USG examinations were conducted by GE $109 \operatorname{logiq} 9$ and Toshiba applio using 7-12 Mhz linear transducers. MR screening was done with GE signa excite MR (1.5 tesla) instrument 3 cases in which tendinosis of biceps tendon were found by MR were negative. For this condition by USG and conversely 8 cases found to be positive for this disorder by USG were found to be negative by MR. (Table 2 ). Kappa coefficient of concordance was, 0,614 which was statistically not reproducible. Specifity of USG was $92 \%$ and sensitivity was $0 \%$ (Table 3). 2 of 5 patients with partial rupture of biceps tendon were signified by USG (Table 4). Sensitivity of USG for partial rupture of biceps tendon was found to be $40 \%$ and specifity was $100 \%$ (Table 5). This is moderately reproducable when kappa coefficient of concordance is considered. Biceps synovitis or effusion was detected in 40 patients by MR while this number was 14 by USG. 4 patients detected with tenosynovitis or effusion by USG were found to be negative for this disorder by MR (Table 6). Sensitivity of USG for biceps tendon synovitis is $35 \%$ and specifity is $93 \%$ (Table 7)

USG is a cheap, non-invasive diagnostic (dependent on radiologist's experience) modality which should be used for patiens with shoulder pain before or synchronously with MR. So getting a rapid diagnosis for biceps tendon disorders shall be facilitated in a cost effective manner.

Anahtar Kelimeler: Biseps tendonu, omuz, ultasonografi, tendinit Keywords: Biceps tendon, shoulders, ultrasoundography, tendinitis 


\section{GíRIŞ̧}

En çok kullanılan eklemlerden olması ve içerdiği yumuşak dokuların yaşlanması sonucu ortaya çıkan dejenerasyon nedeniyle, omuz eklemini ilgilendiren hastalıklar sık görülmektedir. Klinik ve fizik muayene bulguları muhtemel tanıya işaret edebilmesine rağmen çoğu zaman tanısal değildir. Bu nedenle fizik muayene bulgularının çoğunlukla radyolojik görüntüleme yöntemleri ile desteklenmesi gerekmektedir. Omuz ağrısı ve disfonksiyonunun en sık nedeni rotator kaf ve biseps tendon patolojileri olup yakın zamana kadar tanıda tek yöntem olarak artrografi kullanılmaktaydı. Ancak 1980'li yıllardan itibaren non-invaziv yöntemler olan Ultrasonografi (USG) ve Manyetik Rezonans (MR) görüntüleme. artrografinin kullanımını azaltmıştır. Omuz ağrısı ve disfonksiyonu şikâyetiyle başvuran hastalarda öykü, fizik muayene ve direkt grafiler sonrası ilk başvurulması gereken yöntem USG incelemesi olmalıdır. MR, diğer görüntüleme yöntemlerine göre yumuşak doku rezolusyonunun üstünlüğü, iyonizan radyasyon içermemesi, hasta pozisyonunu değiştirmeden kesit planının değiştirilebilmesi; yani multiplanar görüntüleme gibi avantajları nedeniyle omuz ağrısına yönelik incelemeler arasında ön sıralarda yer almaktadır. Ancak gerçek zamanlı inceleme olanağı, ucuz ve kullanışlı olması, rotator kaf ve biseps tendon patolojilerini yüksek doğrulukla tespit edebilmesi ve değişik pozisyonlarda inceleme olanağ gibi nedenlerle USG'nin üstün olduğu taraflar mevcuttur. Biz bu çalışmamızda omuz eklemi şikâyetlerinin sık nedenlerinden olan Biseps tendon patolojilerinin değerlendirilmesinde USG ve MR görüntüleme yöntemlerini birbirleriyle karşılaştırdık. Çalışmamızda yüksek tanı değeri tartışılmayan ve pek çok patolojide tanı açısından Gold standart kabul edilen MR bulgularına USG inceleme ile hangi oranda yaklaşabileceğimizi araştırdık. Böylelikle hastaların inceleme konforu, maliyet etkinlik ve inceleme süresi açısından USG ile öncelikle değerlendirilmesi gerekliliğini vurgulamaya çalıştık.

Anatomi: Muskulus (M) biseps brachi kolun ön tarafında bulunan iki başlı yüzeyel bir kastır. Kasın bölümleri uzunluklarına göre isimlendirilmiştir. Kısa başı kaput breve, yassı ve kısa bir tendonla korakobrakialis kası ile birlikte prosesus korakoideusun ucundan başlar. Kaput longum ise, tuberkulum supraglenoidaleden uzun bir tendonla başlar. $\mathrm{Bu}$ uzun tendon omuz eklemi kapsülünün iç yüzünde sinovial bir kılıfla sarılı olarak humeral intertuberkuler sulkusta aşağıya doğru iner. Fibröz kapsülün alt kısmındaki bir delikten üzerini saran kılıfla (vajina tendinis intertuberkularis) birlikte geçer. $\mathrm{Bu}$ kılıf fibröz kapsülden birkaç $\mathrm{cm}$ aşağıda kas tendonuyla birleşerek sonlanır. Biseps tendonunun sulkus intertuberkulariste kalmasını ligamentum transversum humeri ve $M$. pektoralis majordan gelen bir kısım bağ dokusu lif sağlar. Kasın iki başı birbirine yaklaşarak aşağı iner ve dirsek eklemininin yaklaşı $8 \mathrm{~cm}$ superior kesiminde birleşir. Bundan sonra tek kas olarak devam eder ve radius kemiğindeki tuberositas radii'nin posterior kısmında sonlanır. Biseps kası kol sabit ise ön kola, ön kol sabit ise kola dirsek ekleminde fleksiyon yaptırır. Kontraksiyon yaptığında tuberositas radii'yi ön tarafa getirir ve önkol ile el supinasyon yapar. $\mathrm{Bu}$ nedenle önkol ve elin en güçlü supinatorudur. Kasın innervasyonu nervus musculocutaneus tarafindan gerçekleştirilir. \%10 oranında kasın üçüncü bir başı bulunabilir. Üçüncü baş genelde brakial kasın üst iç kısmından başlar, aşağıda bisipital aponöraz ve esas kasın tendonunda sonlanır $(1,2)$.

Ultrasonografi: Ucuz, etkili, hızlı, dinamik ve noninvaziv bir tanı aracidır. Rotator kaf ve biseps tendon lezyonlarında tanı aşamasında yüksek katkı sağlamaktadır. USG tendon bütünlüğünün değerlendirilmesinin yanı sıra tendon kalınlığg, hareket kabiliyeti, retraksiyon miktarı hakkında da bilgi verir. Omuz USG incelemesinde yüksek frekanslı (7-12 
$\mathrm{MHz}$ ) problar kullanılır. Bu probların kullanımını kısıtlayan faktörler olarak dar yüzeyel görüntüleme alanı ve tendon anizotropisi sayılabilir (3). İnceleme sırasında probun tendona göre açısı tendon ekojenitesini belirleyen faktördür. Probun tendon ile yaptığı açı $90^{0}$ 'den saptığında tendon hipoekoik görünür ve yanlış pozitif sonuçlar alınabilir $(4,5)$.

\section{Manyetik Rezonans Görüntüleme: Yumuşak} dokuların görüntülenmesinde yüksek rezolusyona sahip olup aynı zamanda multiplanar inceleme olanağı sunar. Birçok klinik durumda artrografinin yerini almıştır. Yüzeyel koil kullanımı ve yüksek rezolusyonlu görüntüleme omuzun normal kompleks anatomisinin ve patolojilerinin detaylı analizine olanak verir. İnstabiliteyi, rotator kaf ve biseps tendon patolojilerini, iskemik kemik nekrozunu, kalsifiye tendiniti ve intraartiküler osteokartilajinöz yapıları gösterebilir. Biseps tendonu kaynaklı omuz ağrısı nedenlerinin başlıcaları; kılıfta effüzyon, kalsifik tendinit, bisipital tendinit, uzun başın parsiyel ve total rüptürü olarak siralanabilir.

\section{GEREÇ VE YÖNTEM}

Çalışmamıza Ankara Numune Eğitim ve Araştırma Hastanesi Radyoloji bölümünde omuz MR incelemesi yapılan omuz ağrısı ile başvurmuş 105 hasta dâhil edilmiştir. Hastaların USG incelemeleri Kazan Devlet Hastanesi ve Ankara Numune Eğitim ve Araştırma Hastanesi'nde MR görüntülemeden bağımsız olarak değerlendirilmiştir. Olguların 40'1 erkek, 65'i kadın olup yaşları 21 ile 81 arasında değişmekteydi. Ortalama yaş 55,9'du. USG inceleme GE logiq 9 ve Toshiba applio cihazlarında 7-12 $\mathrm{MHz}$ lineer transduserler ile yapıldı. MR görüntüleme GE 1,5 Tesla Signa Excite MR cihazı ile gerçekleştirildi. Hasta supin pozisyonda iken omuz koili ile görüntüler alındı. Aksiyel PD sekanslar, koronal PD-T2 FS sekanslar, koronal T1 FSE sekanslar, saggital PD FS sekanslar kullanıldı.

\section{BULGULAR}

Çalışmamızda hastaların klinik bulguları, omuz USG ve MR görüntüleri değerlendirildi. Omuz ağrısı nedeniyle başvuran 105 olgu USG ve MR görüntüleme ile incelendi. Daha sonra bulgular karşılaştırıldı. Bulgular biseps tendonu için normal, biseps sinoviti veya effüzyonu, kalsifik tendinit, parsiyel ve komplet rüptür olarak kategorize edildi. MR'da biseps tendonu tendinozisi saptanan 3 olguda USG'de tendinozis saptanamamış olup, USG'de tendinozis saptanan 8 olgu MR'da tendinozis açısından negatif bulunmuştur (Tablo 2).

Tablo 1: 105 olgunun USG ve MR inceleme sonuçları

\begin{tabular}{lcc}
\hline RADYOLOJIK YÖNTEM & USG & MR \\
\hline Normal biseps tendonu & 80 & 60 \\
Biseps sinoviti veya effüzyonu & 18 & 40 \\
Biseps tendinozis & 8 & 3 \\
Biseps tendonu parsiyel rüptürü & 2 & 5 \\
Biseps tendonu komplet rüptürü & 0 & 0 \\
Biseps tendonu kalsifik tendiniti & 1 & 1 \\
\hline
\end{tabular}


Tablo 2. Biseps tendonu tendinozisin USG ve MR'da olgulara göre dağılımı

\begin{tabular}{|c|c|c|c|c|}
\hline \multirow{5}{*}{ MR tendinozis } & & \multicolumn{2}{|c|}{ USG Biseps tendinozis } & \multirow{2}{*}{$\begin{array}{c}\text { Toplam } \\
\text { Yok }\end{array}$} \\
\hline & & Yok & Var & \\
\hline & Yok & 94 & 8 & 102 \\
\hline & $\%$ MR tendinozis & 92,2 & 7,8 & 100 \\
\hline & $\%$ USG tendinozis & 96,9 & 100,0 & 97,1 \\
\hline & Var & 3 & 0 & 3 \\
\hline & $\%$ MR tendinozis & 100,0 & 0 & 100,0 \\
\hline & $\%$ USG tendinozis & 3,1 & 0 & 2,9 \\
\hline & Toplam & & 8 & 105 \\
\hline & $\%$ MR tendinozis & 92,4 & 7,6 & 100,0 \\
\hline & $\%$ USG tendinozis & 100,0 & 100,0 & 100,0 \\
\hline
\end{tabular}

Kappa uyum katsayısı 0,614 olup, istatistiksel olarak uyumsuz bulunmuştur. USG’nin özgüllük değeri \%92 olup duyarlılık değeri \%0'dır (Tablo 3). MR'da biseps tendonu parsiyel rüptürü olan 5 hastanın 2'si USG'de saptanmıştır (Tablo 4).

Tablo 3. USG'nin biseps tendonunda tendinozis için istatiksel değeri

\begin{tabular}{lccc}
\hline Prevalans & 0,0286 & \multicolumn{2}{c}{$\% 95$ Güven Aralığı } \\
\hline Duyarlılık & 0,0000 & 0,0000 & 0,5615 \\
Özgüllük & 0,9216 & 0,8528 & 0,9597 \\
Pozitif öngörü değeri & 0,0000 & 0,0009 & 0,0440 \\
Negatif öngörü değeri & 0,9691 & 0,9094 & 0,9914 \\
\end{tabular}

Tablo 4. Biseps tendonu parsiyel rüptürünün USG ve MR'da olgulara göre dağılımı

\begin{tabular}{|c|c|c|c|c|}
\hline \multirow{5}{*}{ MR parsiyel rüptür } & \multirow[b]{3}{*}{ Yok } & \multicolumn{2}{|c|}{ USG Biseps tendon parsiyel rüptür } & \multirow{2}{*}{$\frac{\text { Toplam }}{\text { Yok }}$} \\
\hline & & Yok & Var & \\
\hline & & 100 & 0 & 100 \\
\hline & \% MR parsiyel rüptür & 100,0 & 0,0 & 100 \\
\hline & \% USG parsiyel Rüptür & 97,1 & 0,0 & 95,2 \\
\hline & Var & 3 & 2 & 5 \\
\hline & $\%$ MR parsiyel rüptür & 60,0 & 40,0 & 100,0 \\
\hline & \% USG parsiyel rüptür & 2,9 & 100,0 & 4,8 \\
\hline & Toplam & 103 & 2 & 105 \\
\hline & $\%$ MR parsiyel rüptür & 98,1 & 1,9 & 100,0 \\
\hline & \% USG parsiyel rüptür & 100,0 & 100,0 & 100,0 \\
\hline
\end{tabular}


USG'de biseps tendonu parsiyel rüptürü için duyarlılık \%40,özgüllük \%100 olarak bulunuştur (Tablo 5).

Tablo 5. USG'nin biseps tendonunda parsiyel rüptür için istatiksel değeri

\begin{tabular}{llcc}
\hline Prevalans & 0,0476 & \multicolumn{2}{c}{$\% 95$ Güven Aralı̆̆ } \\
\hline Duyarlılık & 0,4000 & 0,1176 & 0,7693 \\
Özgüllük & 1,0000 & 0,9630 & 1,0000 \\
Pozitif öngörü değeri & 1,0000 & 0,9560 & 0,9991 \\
Negatif öngörü değeri & 0,9709 & 0,9119 & 0,9923 \\
\hline
\end{tabular}

Kappa uyum katsayısına göre orta derecede uyumludur. MR'da 40 hastada biseps sinoviti veya effüzyonu görülürken, USG'de 14 hastada saptanmıştır. USG'de tenosinovit veya effüzyon saptanan 4 hastada MR'da tenosinovit veya effüzyon saptanmamıştır (Tablo 6). USG'nin biseps tendon tenosinoviti veya effüzyonu için duyarlılık değeri \%35, özgüllük değeri \%93'tür (Tablo 7). Biseps tendonunda kalsifik tendinit bulunan tek bir olgu hem USG hem de MR'da saptanabilmiştir. Ancak istatistiksel değerlendirme bu hasta grubu için yapılamamıştır. Biseps tendonunda komplet rüptür ise USG ve MR incelemelerinde saptanmamış olup istatistiksel analiz yapılamamıştır.

Tablo 6. Biseps tendonu sinoviti veya kılıfta effüzyonun USG ve MR'da olgulara göre Dağılımı

\begin{tabular}{llccc}
\hline & & \multicolumn{2}{c}{$\begin{array}{c}\text { USG Biseps tendon sinovit veya } \\
\text { effüzyon }\end{array}$} & Toplam \\
\cline { 3 - 4 } & & Yok & Var & Yok \\
\cline { 2 - 4 } $\begin{array}{l}\text { MR biseps sinoviti veya } \\
\text { effüzyon }\end{array}$ & Yok & 61 & 4 & 65 \\
& \% MR sinovit-effüzyon & 93,8 & 6,2 & 100 \\
& \% USG sinovit-effüzyon & 70,1 & 22,2 & 61,9 \\
\hline Var & 26 & 14 & 40 \\
& \% MR sinovit-effüzyon & 65,0 & 35,0 & 100,0 \\
& $\%$ USG sinovit-effüzyon & 29,9 & 77,8 & 38,1 \\
\hline & Toplam & 87 & 18 & 105 \\
& \% MR sinovit-effüzyon & 82,9 & 17,1 & 100,0 \\
& $\%$ USG sinovit-effüzyon & 100,0 & 100,0 & 100,0 \\
\hline
\end{tabular}

Tablo 7. USG'nin biseps tendon sinoviti veya kılıfta effüzyon için istatiksel değeri

\begin{tabular}{lccc}
\hline Prevalans & 0,3810 & \multicolumn{2}{c}{$\% 95$ Güven Aralığ1 } \\
\hline Duyarlılık & 0,3500 & 0,2213 & 0,5049 \\
Özgüllük & 0,9385 & 0,8522 & 0,9758 \\
Pozitif öngörü değeri & 0,7778 & 0,6841 & 0,8507 \\
Negatif öngörü değeri & 0,7011 & 0,6028 & 0,7846 \\
\hline
\end{tabular}




\section{TARTIŞMA}

Omuz ağrısı kas-iskelet sisteminin en sık karşılaşılan semptomlarından birisidir (6). Omuz ağrısının en sık nedenleri humerus başı ile korakoakromial ark arasında yer alan rotator kaf ve bursanın sıkışması sonucu Biseps tendonuna ait patolojilerdir. Biseps tendiniti olan hastalarda genellikle bisipital oluk düzeyinde ağrı vardır. $\mathrm{Bu}$ klinik durumu impingement sendromu, rotator kaf tendiniti gibi diğer nedenlerden ayırmak çoğu zaman zordur. Fizik muayenede biseps tendonu bozukluklarında biseps oluğu üzerinde noktasal hassasiyet mevcuttur. Kol $10^{0}$ iç rotasyonda iken intertuberkuler sulkus ileri doğru bakar. Bu hassasiyet trigger pointin kolun diş rotasyonuyla laterale doğru hareket ettiği durumlarda biseps patolojisine özgüdür. Patton ve arkadaşları bu harekette hassasiyetin bisipital patoloji için en spesifik bulgu olduğunu belirtmişlerdir (7). Bisipital tendinit bisipital oluk içerisinde tendonun devamlı sürtünmesi ve kronik travmaya maruz kalması sonucunda meydana gelir. Özellikle başın üzerinde firlatma ve vuruş yapan sporcularda görülür. Bisipital tendinitin tek başına görülmesi nadir olup genellikle supraspinatus tendiniti, subakromial sıkışma sendromu veya glenohumeral instabilite ile birlikte bulunur (811). Klinik ve fizik muayene bulguları çoğu zaman omuz ağrısı nedenlerini ortaya koymakta yeterli olmaz. $\mathrm{Bu}$ hastalarda direkt grafi, USG ve MR incelemeleri tanıya son derece katkı sağlamaktadır. Patton ve arkadaşları primer biseps tendinitli hastalarda direkt grafi bulgularının normal olarak saptandığını bildirmiştir (7). Biseps tendonu değerlendirilmesinde artrografi de kullanılmakta olup; USG ve MR kullanımı sonrası popülaritesini kaybetmiştir. Middleton ve arkadaşları USG'nin biseps tendon patolojilerini saptamada artrografiden daha başarılı olduğunu bildirmiştir (12). Omuz USG ilk kez 1979 y1lında Selzer tarafindan artrografiye alternatif olarak uygulanmıştır (13). Günümüzde MR gibi pahalı ve artrografi gibi invaziv yöntemler kullanılmadan da USG ile birçok omuz lezyonuna tanı koyabiliriz.
Ancak doğru tanı koymak için tecrübe ve bilgi birikimi yanında kullanılan cihazın teknik açıdan yeterliliği ile de ilgilidir. USG'nin başlıca dezavantajları kullanıcı bağımlı olması, kemik yapıları ve labrumun tamamını değerlendirmede yetersiz kalması ve ligamentleri optimal düzeyde görüntüleyememesidir (14). MR noninvaziv olması ve ayrıntılı inceleme olanağıyla biseps tendonunu değerlendirmede mükemmel bir inceleme aracıdır. Ancak maliyet ve zaman kazanımı açısından USG'ye üstünlüğü yoktur. Çalışmamızda biseps tendonunda effüzyon veya tenosinovit için duyarlılık $\% 35$, özgüllük \%93 olarak bulunmuştur. Bizim çalışmamızda biseps tendonunda tendinozis için istatistiksel uyumsuzluk saptanmıştır. Ancak biseps tendonu parsiyel rüptüründe duyarl1lık \%40, özgüllük \%100 olarak saptanmıştır. Olgularımız içerisinde komplet biseps tendon rüptürü saptanmadığından istatistik analiz yapılmamıştır. Biseps tendon patolojilerinde MR ve USG arasinda Rotator kaf patolojilerine kıyasla duyarlılık ve özgüllük değerleri bildirilenden düşüktür. Bu fark USG'nin kişiye bağımlı olmasından kaynaklanabilir. USG incelemesi biseps tendon patolojilerinde ucuz, kolay ve tanı koydurucu bir yöntem olmakla birlikte kullanıcı tecrübesi önemlidir (15). Buradan yola çıkarak omuz ağrısıyla başvuran hastalarda ilk radyolojik incelemenin USG olması; ancak tanının MR ile desteklenmesi gerektiği kanısındayız.

\section{KAYNAKLAR}

1. Snell RS. Klinik Anatomi 5. Baskı Cev. Ed. Yıldırım M. Nobel Tıp Kitabevleri. Yüce Yayınlar1.1998.

2. Gray H: Anatomy of the Human Body. 37. Bask1, Churchill Livingstone, New York. 1989.

3. Fornage BD, The hypoechoic normal tendon, a pitfall, J Ultrasound Med. 1987, 6; 19- 22.

4. Erden I, Kas-İskelet Manyetik Rezonans Uygulamaları. Ankara, 2004; 6-15. 
5. Rumack C. Diagnostic Ultrasound, 3rd edition, 2005; 889-908.

6. Pope DP, Craft PR. The frequency of restricted range of movement in inviduals with self-reported shoulder pain: Result from a population based survey. Br J Rheumatol. 1996; 35: 1137-41.

7. Patton WC, McCluskey GM. Biceps tendinitis and subluxation artroscopy. The Journal of Arthroskopic and Related Surgery. 2001; 20(3); 505-29.

8. Poppen NK. Soft-tissue lesions of the shoulder. Chapman MW, Madison M (Ed.). Operative Orthopaedics. JB Lippincott Company, Philadelphia, 1993: 1651-71.

9. Dalton SE. The shoulder. In: Klippel JH, Dreppe PA, editors. Rheumatology. St. Louis: Mosby, 1994: 5815-16.

10. Braddom RL, Buschbacher RM, Dumitru D, Johnson EW, Matthews D, Sinaki M (Ed.): Physical Medicineand rehabilitation. WB Saunders Company, Philadelphia, 1996, 756-81.

11. Paynter KS. Disorders of the long head of the biceps tendon. Phys Med Rehabil Clin N Am. 2004; 15: 511-28.

12. Middleton WD, Reinus WR, Totty WF. Ultrasonographic evaluation of the rotator and biceps tendon. J Bone Joint Surg. 1986; 68: 440-50.

13. Seltzer SE, Finberg HJ, Weissman BN, Kido DK, Collier BD. Arthrosonography: Grayscale ultasound evaluation of the shoulder. Radiology 1979; 132: 467-68.

14. Verim S, Sarı S. TOTBİD Dergisi 2013; 12(1): 712.

15. ÇEVİKOL C. Türkiye Klinikleri J PM\&R-Special Topics. 2014; 7(2): 42-51. 